\title{
Erratum to: Structure and Reactivity of the Distonic and Aromatic Radical Cations of Tryptophan
}

\author{
Andrii Piatkivskyi, ${ }^{1}$ Sandra Osburn, ${ }^{1}$ Kendall Jaderberg, ${ }^{1}$ Josipa Grzetic,${ }^{2,3,4}$ \\ Jeffrey D. Steill, ${ }^{2,3,4,6}$ Jos Oomens, ${ }^{2,3,4}$ Junfang Zhao, ${ }^{5}$ Justin Kai-Chi Lau, ${ }^{5}$ \\ Udo H. Verkerk, ${ }^{5}$ Alan C. Hopkinson, ${ }^{5}$ K. W. Michael Siu, ${ }^{5}$ Victor Ryzhov ${ }^{1}$
}

${ }^{1}$ Department of Chemistry and Biochemistry, and Center for Biochemical and Biophysical Studies, Northern Illinois University, DeKalb, IL 60115, USA

${ }^{2}$ FOM Institute for Plasma Physics, Rijnhuizen 14, 3439 MN Nieuwegein, The Netherlands

${ }^{3}$ University of Amsterdam, Science Park 904, 1098 XH Amsterdam, The Netherlands

${ }^{4}$ Institute for Molecules and Materials (IMM), FELIX facility, Radboud University Nijmegen, Heyendaalseweg 135, 6525AJ

Nijmegen, The Netherlands

${ }^{5}$ Department of Chemistry and Centre for Research in Mass Spectrometry, York University, Toronto, ON, Canada

${ }^{6}$ Sandia National Laboratories, Livermore, CA 94550-0969, USA

\section{Erratum to: J Am Soc Mass Spectrom \\ DOI 10.1007/s13361-013-0594-0}

An incorrect version of Figure 2 was shown in our recently published article. The correct figure and caption are given below. The authors regret this error.

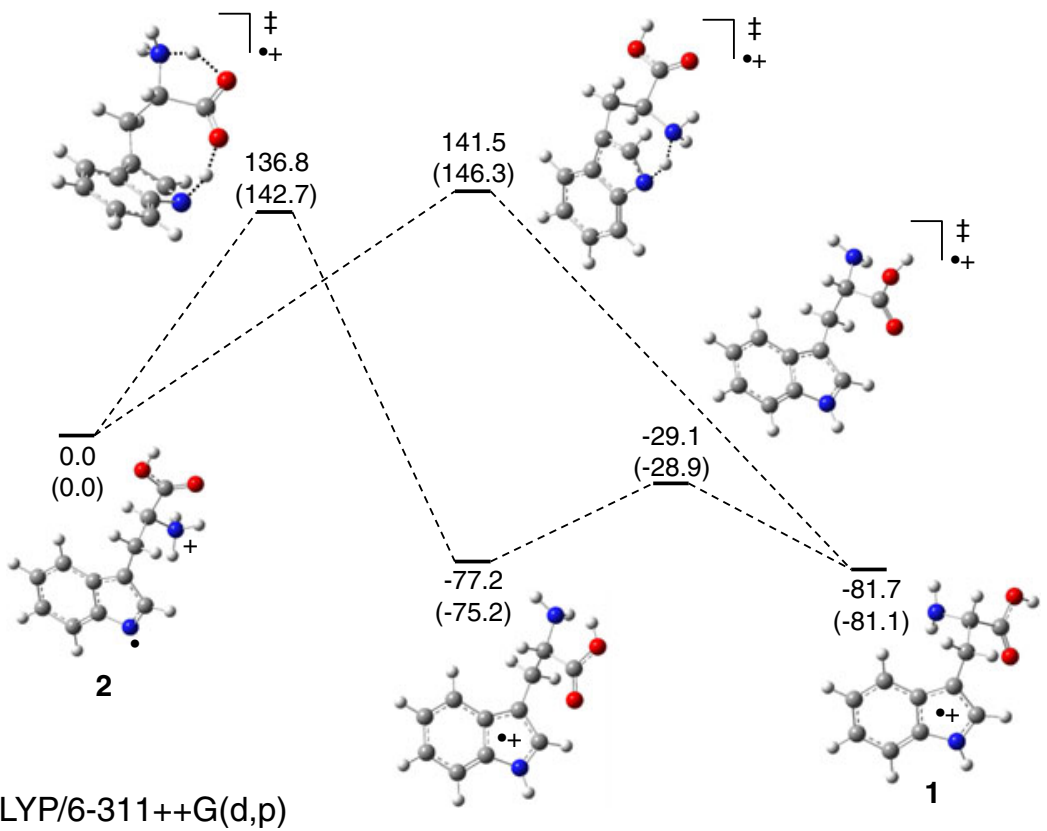

Figure 2. B3LYP/6-311++G(d,p) -calculated reaction pathways for the rearrangement of 2 into 1. Values reported are $\Delta H$ at $0 K$ and $(\Delta G$ at $298 K)$

The online version of the original article can be found at http://dx.doi.org/ 10.1007/s13361-013-0594-0.

Correspondence to: Udo H. Verkerk; e-mail: uverkerk@yorku.ca; Alan C. Hopkinson; e-mail: ach@yorku.ca; Victor Ryzhov; e-mail: ryzhov@niu.edu 